\title{
Cuatro omisiones del "Directorio para la CATEQUESIS"
}

\section{FOUR OMISSIONS OF THE "DIRECTORY FOR CATECHESIS"}

\author{
Enrique García Ahumada, fsc ${ }^{1}$ \\ Seminario Pontificio Mayor del Arzobispado de Santiago \\ Chile
}

Resumen

El Directorio para la Catequesis se reconoce documento importante del magisterio eclesial. Sin embargo, al no haberse consultado a las Conferencias Episcopales, como se hizo al preparar el Directorio General para la Catequesis de 1997 y el Catecismo de la Iglesia Católica de 1992, incurre en omisiones, de las que se seńalan cuatro, justificando su importancia.

\section{Palabras clave}

Catequesis social, revelación, magisterio eclesial, antropología cultural, didascalia

\begin{abstract}
The Directory for Catechesis is esteemed an important document of the ecclesial teaching. However, as Bishops Conferences were not consulted as it was done when preparing the General Directory for Catechesis in 1997 and the Catechism of the Catholic Church, it falls into omissions, from which four are shown, pointing out their importance.
\end{abstract}

\section{KeYWORdS}

Social catechesis, revelation, eclesial teachings, cultural anthropology, didascalia 
El Pontificio Consejo para la Promoción de la Nueva Evangelización publicó el 25 de junio de 2020 el Directorio para la Catequesis. Aquí, como en todos los documentos del magisterio eclesial, no se cita por páginas sino por números de párrafo, por existir diferentes ediciones simultáneas o sucesivas; para los textos bíblicos hay un modo oficial de señalar sus referencias, y para las referencias a la Suma Teológica de Santo Tomás de Aquino hay una forma aceptada, jamás por páginas. Sus 425 párrafos en 250 páginas amplían y actualizan el magisterio eclesial sobre catequesis, mostrándolo ser importante documento pastoral. No se consultó al elaborarlo a las Conferencias Episcopales ni a las Sociedades de Catequetas nacionales y continentales que las asesoran, por lo cual incurre en omisiones, de las cuales aquí se señalan cuatro explicando su importancia y sugiriendo corregirlas de hecho en las iglesias locales.

\section{OMITE LA REVELACIÓN DIVINA PRIVADA UNIVERSAL}

El Directorio para la Catequesis afirma sin justificación: "Desde el comienzo de la creación Dios nunca ha dejado de comunicar al hombre este plan de salvación y de mostrarle los signos de su amor; e incluso 'Si el hombre puede olvidar o rechazar a Dios, Dios no cesa de llamar a todo hombre a buscarle para que viva y encuentre la dicha"' (Directorio para la Catequesis, \#11). La cita final de ese pasaje, tomada del Catecismo de la Iglesia Católica, número 30, es declaración piadosa indocumentada. El fundamento de que Dios nunca ha dejado de atraer al hombre a la salvación, aunque no le haya comunicado su plan de salvación como dice extrañamente el Directorio, es la revelación divina no pública como la comenzada con Abrahán, sino privada y universal, desde que hay seres humanos. Esa revelación divina privada universal, sin ser reconocida hasta ahora en la literatura teológica ni en la catequística, está en el Evangelio: " $L a$ Palabra era la luz verdadera que ilumina a todo hombre, cuando viene a este mundo"(Jn 1:9). Así dice la traducción más reciente de la Biblia 
de Jerusalén (2009) conforme al original griego y a la Vulgata Latina, como se proclamaba en latín en el Prólogo del Evangelio según san Juan al final de la misa preconciliar: "Erat lux vera quae illuminat omnem hominem venientem in hunc mundum" (Lefebvre, 1962, p. 1000). La edición de 1980 de la Biblia de Jerusalén también declaraba, sin darle ese nombre, la revelación divina privada universal al decir: "La Palabra era la luz verdadera que ilumina a todo hombre que viene a este mundo". Ejemplo importante de incomprensión de la revelación divina privada universal es la Nova Vulgata (Juan Pablo II, 1979) que traduce: "Erat lux vera, quae illuminat omnem hominem, veniens in mundum", que puede entenderse referente al Verbo ya encarnado y no a todo hombre.

Está demostrada la catastrófica consecuencia en América de esta incomprensión de texto tan claro, al difundir durante siglos la convicción de estar condenados todos los humanos que no conocieron a Jesucristo (García Ahumada, 2018, pp. 140-142). Según implica el Evangelio según san Juan, Dios se comunica aun con humanos carentes de lenguaje oral. Siglos demoraron los animales racionales en dejar de comunicarse a gritos, chillidos y golpes hasta poner nombres a las cosas inventando sustantivos repetibles, ponérselo a las cualidades de las cosas inventando adjetivos repetibles y acordables en familias y pueblos, y ponérselos también a las acciones inventando verbos repetibles y establecidos para sus comunidades desde la menor que es la familia hasta los pueblos más grandes y dominadores, con lo cual, más algunos otros elementos verbales, se formaron los idiomas.

El Evangelio según san Lucas atestigua que Juan Bautista prenato, sin recibir palabra, percibió a Dios: "En cuanto oyó Isabel el saludo de María, saltó de gozo el niño en su seno”(Lc 1:41). ¿Qué razón hay para que aun sin tener uso de la palabra los humanos hayan podido recibir revelaciones de Dios? Dios "quiere que todos los hombres se salven" (1 Tm 2:4). En este asunto es muy relevante el texto fundamental sobre la gloria de Dios: "Moisés dijo a Yahvé: 'Déjame ver tu gloria'. Él le contestó: 'Yo haré pasar ante tu vista toda mi bondad"' (Ex 33:1819a). Me asombra no haber encontrado sino un comentarista sobre 
este texto: Santo Tomás, sacando de él la conclusión de que "la gloria de Dios es la manifestación de su bondad" (Aquino, 1975, Parte I, cuest. 65, art. 2). En consecuencia, nosotros damos gloria a Dios con todo acto bondadoso. Todos los judeocristianos deberíamos ser reconocidos como muy bondadosos, lo cual es espiritualmente muy motivador. No he visto aludir ese texto definitorio de la gloria de Dios ni siquiera a quienes meritoriamente tienen por lema hacerlo todo ad majorem Dei gloriam: los jesuitas.

En resumen, sin lenguaje verbal Dios hace sentir a todos su bondad sugiriendo de algún modo extenderla para salvarse. Obviamente, esta comunicación divina privada universal generó las religiones primitivas y después grandes religiones más elaboradas. Misioneros y catequistas desde hace siglos reconocemos que el Espíritu de Dios está en nuestros interlocutores desde antes de acercarnos a ellos. La historia de la salvación no empezó con Abrahán, sino desde que existe el homo sapiens. En consecuencia, corresponde explicar la revelación divina privada universal en la catequesis y en todo el ministerio de la Palabra.

\section{No incluye la CATEQUesis EN LA DidAsCalia, FUNCIÓN ESENCIAL DE LA IGLESIA}

Al definir la identidad de la catequesis, el Directorio le atribuye insignes características: "es un acto de naturaleza eclesial, nacido del mandato misionero del Señor (Mt 28:19-20)"; “acompaña, educa y forma en la fe y para la fe, introduce en la celebración del Misterio"; es "etapa privilegiada del proceso de evangelización” (DC, \#55-56). Pero no incluye la catequesis en la didascalia, función esencial de la Iglesia, cuestión muy olvidada y recientemente defendida con argumentación bíblica (García Ahumada, 2019).

Lo grave es que la práctica pastoral actual no considera función esencial de la Iglesia formar cristianos. Al celebrar Bautismo y Confirmación hay unción con el santo crisma proclamando: "Dios 
todopoderoso, Padre de nuestro Señor Jesucristo, que les has dado nueva vida por el agua y el Espíritu Santo, y les has concedido el perdón de los pecados, les unge con el crisma de la salvación, para que, incorporados a su pueblo santo, permanezcan como miembros de Cristo sacerdote, profeta y rey hasta la vida eterna". No menciona el rol de educar la fe conferido o acrecentado a los sujetos de esos sacramentos de iniciación cristiana. Es discutible si el común de los bautizados y bautizadas se sienten sacerdotes, profetas y reyes en algún sentido y lo ejercen.

En cambio, propongo proclamar en la celebración del Bautismo y de la Confirmación que: “... incorporados a la Iglesia madre y maestra enviada a evangelizar, crezcan como discípulos misioneros, miembros de Cristo Salvador". El rito bautismal propondría una clara concepción de Iglesia evangelizadora fundamentada y comprometedora, cosa hoy inexistente. Eso favorecería la pastoral del bautismo de niños, empeñada en que los padres quieran iniciarlos y educarlos como cristianos. En ambos sacramentos la preparación de padrinos como educadores y evangelizadores sacaría también provecho del rito. Los liturgistas podrían lograr esta innovación.

\section{Omite la antropología cultural en la FORMACIÓN DE CATEQUISTAS}

Dice el Directorio: "Junto con la fidelidad al mensaje de fe, el catequista está llamado a conocer a la persona concreta y el contexto sociocultural en el que vive. Como todos los cristianos, aun más los catequistas 'vivan en muy estrecha unión con los demás hombres de su tiempo, y esfuércense en penetrar su manera de pensar y sentir, cuya expresión es la cultura' (Gaudium et spes, \#62). Este conocimiento llega a través de la experiencia y de la continua reflexión sobre ella, pero también gracias a la preciosa contribución de las ciencias humanas, a la luz de los principios de la doctrina social de la Iglesia. Entre las ciencias debe darse especial importancia a la sicología, la sociología, 
la pedagogía, las ciencias de la educación y de la comunicación. La Iglesia se siente invitada a dejarse interpelar por estas ciencias por su valioso aporte que dan a la formación de catequistas como a la tarea catequética misma. De hecho, la teología y las ciencias humanas se enriquecen mutuamente" (DC, \#146). No nombra la antropología cultural, ciencia constituida desde mediados del siglo XX, dedicada a identificar la cultura de grupos y comunidades humanas.

En Chile, con la ayuda de una tesis presentada en la Universidad de Lovaina para la licenciatura en Catequesis y Pastoral (García Ahumada, 1981), desde 1982 se forma a los catequistas en antropología cultural en las diócesis, a medida que los obispos y sus equipos de formadores reconocen su necesidad. En ausencia de elementos de esta disciplina, se observan extravíos en la comprensión y práctica de la inculturación de la revelación divina, practicada ejemplarmente por Jesús en la cultura israelita, y de la evangelización de las culturas, tan afectadas ahora por la secularización.

La experiencia muestra que es factible una información básica sobre esta disciplina. Basta primero distinguirla respecto de la antropología teológica presente en el Antiguo Testamento al ilustrar la relación del hombre con Dios; de la antropología filosófica creada por los griegos al admirar el contraste del hombre con los demás seres vivientes, y de la antropología física o biológica que distingue a los diversos colectivos humanos por sus rasgos corporales. Permite conocer las maneras de vivir y actuar de las comunidades humanas antiguas y actuales. Aclaradas esas distinciones para entender de qué antropología se trata sin confundirlas ni mezclarlas, se aprende a acercarse a la cultura de un pueblo o de subgrupos dentro de él mediante pautas científicas para observar una comunidad. Eso permite identificar culturas para crear intervenciones pastorales acertadas. El Directorio, al carecer de aportes de las conferencias episcopales bien asesoradas, no pudo valorar las contribuciones de la antropología cultural a la catequesis, ya en uso al menos en partes de Europa y de América.

Una vez comprendida básicamente la antropología cultural y su servicio a la acción eclesial, se puede evangelizar la cultura académica 
en las diferentes asignaturas de la educación cristiana escolar. El Directorio para la Catequesis trata también de la escuela católica y de los educadores católicos a los cuales interesa la experiencia aquí presentada (DC, \#309-312). Se pueden afrontar con eficacia los conflictos señalados por el Directorio entre la ciencia y la fe, para los cuales el documento aporta principios generales:

El continuo progreso de las ciencias, cuyos resultados masivos afectan a la sociedad, marca fuertemente a la cultura contemporánea. Las personas, fascinadas por una mentalidad científica, se preguntan cómo la ciencia puede conjugarse con los datos de la fe. Surgen así cuestiones sobre el origen del mundo y de la vida, la función del hombre sobre la tierra, la historia de los pueblos, las leyes que gobiernan la naturaleza, el carácter espiritual que hace singular cada vida humana entre los demás vivientes, el progreso humano y el futuro del planeta. Estas cuestiones, en cuanto expresión de la búsqueda de sentido, tocan los aspectos de la $\mathrm{fe}, \mathrm{y}$ por eso interpelan a la Iglesia. Diversos documentos del Magisterio han tratado directamente la relación entre la ciencia y la fe (DC, \#354).

Aun reconociendo los excesos ideológicos del reduccionismo naturalista y del cientificismo, bien distintos del conocimiento científico como tal, y, además, conscientes de los problemas éticos que pueden surgir de la aplicación de algunos resultados de la ciencia, el juicio de la Iglesia sobre la cultura científica es positivo, considerándola una actividad con la que el hombre participa en el plan creador de Dios y en el progreso de toda la familia humana. Mientras de un lado 'la evangelización está atenta a los avances científicos para iluminarlos con la luz de la fe y de la ley natural', es cierto que del otro lado 'algunas categorías de la razón y de las ciencias son acogidas en el anuncio del mensaje, esas mismas categorías se convierten en instrumento de evangelización'. Los aparentes conflictos entre conocimiento científico y algunas enseñanzas de la Iglesia son clarificados por la exégesis bíblica y la reflexión teológica, interpretando la Revelación, aplicando una correcta epistemología científica, aclarando equívocos históricos y poniendo en evidencia prejuicios e ideologías (DC, \#355). 
Ya se motiva y se entrena a los docentes de educación básica, media y superior en evangelizar la cultura académica en las siguientes áreas de estudio: preparar al Evangelio con la filosofía (García Ahumada, 2016, pp. 297-300), evangelizar la cultura corporal (pp. 301-304), evangelizar la educación técnica (pp. 304-306), evangelizar la cultura científica (pp. 306-318), evangelizar la cultura matemática (pp. 319324), evangelizar el lenguaje verbal (pp. 324-334), evangelizar al enseñar un idioma extranjero (pp. 334-338), confrontar la fe católica al enseñar historia (pp. 339-349), evangelizar con la música (pp. 350353), evangelizar con las artes plásticas (pp. 353-361), evangelizar la orientación vocacional (pp. 362-364).

\section{Omite la catequesis social}

El Directorio valora el aspecto social de la fe y de la vida cristiana. Admite que "el kerygma tiene un contenido ineludiblemente social" (DC, \#60). Diserta teóricamente sobre el aspecto social de la catequesis:

La catequesis, con la ayuda de la doctrina social de la Iglesia, y adaptando las propuestas a la condición de los sujetos, despliega una mirada evangélica sobre la realidad, y los hace conscientes de la existencia de estructuras de pecado, que tienen un impacto negativo sobre el ambiente y sobre el tejido social. Motiva, además, a los fieles para que actúen en favor del bien común, ya sea en la esfera de la propia cotidianidad o, a escala más amplia, en un compromiso social y político directo. El amor por la sociedad y el compromiso por el bien común son una forma eminente de caridad, que no solo afecta a las relaciones entre los individuos, sino también las 'macrorrelaciones sociales, económicas y políticas' (DC, \#390). Al tratar la catequesis de adultos, dice que existen varias formas, pero se limita prácticamente a explicar las formas de catecumenado (DC, \#261-263). En cambio, la V Conferencia General del Episcopado Latinoamericano y del Caribe realizada en Aparecida, Brasil, en 2007, asumió un compromiso solemne: La V Conferencia se compromete a llevar a cabo una catequesis social incisiva, porque 'la vida cristiana no se expresa solamente en las virtudes personales, sino también en las 
virtudes sociales y políticas'. En América Latina hay larga trayectoria de afrontar situaciones sociales graves con multitudinaria catequesis social (García Ahumada, 1985a, pp. 403-413; 1985b, pp. 543-549; 1986, pp. 216-225). La catequesis social emplea de preferencia el método conciliar de ver, juzgar y actuar (Apostolicam actuositatem, \#29) inventado por el obispo husita Juan Amós Comenio (1592-1670) en su Didáctica Magna (1922), introducido en la Juventud Obrera Católica (JOC) por el abate belga y después cardenal José Cardijn (1882-1967). A diferencia de la sola enseńanza de la doctrina social de la Iglesia, que suele mantenerse teórica, procede mediante diálogo en grupos, aborda situaciones sociales concretas, se funda en abundante y variado contenido bíblico, incluye generalmente celebraciones de la Palabra conducentes a la práctica de la virtud en compromisos de acción eficaz y benéfica para los sufrientes. Es una manera importante y renovadora de practicar la Iglesia en salida propuesta con insistencia por S.S. Francisco. Las manifestaciones multitudinarias de descontento social observables en todas partes del mundo merecen el servicio paciente y eficaz de la Iglesia mediante la catequesis social.

\section{Epílogo}

Las omisiones del Directorio para la Catequesis señaladas han de ser cubiertas en las Iglesias locales en beneficio de la maduración cristiana de nuestras comunidades, y conviene también suplirlas en el magisterio catequético de las diócesis, conferencias episcopales y sínodos.

\section{REFERENCIAS BIBLIOGRÁFICAS}

Aquino, T. de (1975) Suma de teología. Biblioteca de Autores Cristianos. Comenio, J. A. (1922). Didáctica Magna. Reus. 
Congregación para el Clero (1997). Directorio General para la Catequesis. Libreria Editrice Vaticana

Biblia de Jerusalén (1980). Desclée de Brouwer.

Biblia de Jerusalén (2009). Desclée de Brouwer.

García Ahumada, E. (1981). Antropología para personal apostólico. Oficina Nacional de Catequesis.

García Ahumada, E. (1985a). Catequesis social. Catequesis Latinoamericana, 4(15), 543-549.

García Ahumada, E. (1985b). Une catéchèse ouverte à la société en Amérique Latine. Lumen Vitae, 49(4).

García Ahumada, E. (1986). Social Catechesis in Latin America. Lumen Vitae, 41(2).

García Ahumada, E. (2016). Teología de la educación hoy. Universidad Finis Terrae.

García Ahumada, E. (2018). Breve historia de la educación religiosa. Revista de Educación Religiosa, 1(1), 139-142. https://doi. org/10.38123/rer.vli1.29

García Ahumada, E. (2019). La didascalia, olvidada función esencial de la Iglesia. Revista de Educación Religiosa, 2(1), 61-86. https:// doi.org/10.38123/rer.v1i2.19

García Ahumada, E. (2021) Una incisiva catequesis social. Diakom.

Juan Pablo II (1979). Nova Vulgata Bibliorum Sacrorum. Libreria Editrice Vaticana.

Juan Pablo II (1982). Catecismo de la Iglesia Católica. Asociación de Editores del Catecismo-Libreria Editrice Vaticana.

Lefebvre, G. (1962). Misal diario y vesperal. Desclée de Brouwer.

Paulo VI (1970). Concilio Vaticano II. Constituciones, Decretos, Declaraciones, Legislación posconciliar. Biblioteca de Autores Cristianos. 
Enrique García Ahumada, fsc | Cuatro omisiones del "Directorio para la CATEQuesis"

Pontificio Consejo para la Promoción de la Nueva Evangelización (2020). Directorio para la Catequesis. Libreria Editrice Vaticana. V Conferencia General del Episcopado Latinoamericano y del Caribe (2007). Documento Conclusivo de Aparecida. CELAM.

Fecha de recepción: 13 de abril de 2021 Fecha de aceptación: 25 de mayo de 2021 